\title{
$\Omega$
}

Brigitte Fauroux ${ }^{1}$, Goran Markovic ${ }^{2}$

[1]

${ }^{1}$ Pediatric Noninvasive Ventilation and Sleep Unit, Necker University Hospital and

Research Unit INSERM U 955, team 13, Paris, France.

2Institute for Children's Diseases, Clinical Center of Montenegro, Podgorica, Montenegro.

\section{Paediatric long-term noninvasive ventilation: course report}

\section{Faculty}

A. Amaddeo, R. Cutrera, B. Fauroux, S. Khirani,
U. Krivec, H. Prigent, S. Verhulst

\section{Overview}

Use of noninvasive ventilation (NIV) in children is expanding worldwide. A wide range of heterogeneous disorders such as neuromuscular diseases, lung diseases, and upper airway obstructions causing severe obstructive sleep apnoea (OSAS) may benefit from continuous positive airway pressure (CPAP) or NIV. All age ranges may be concerned, from neonates to adolescents. Technical aspects are of major importance in practice: prescribers need to know which equipment (interfaces and devices) may be used in a specific child. Practical training of physicians dealing with children requiring CPAP or NIV is thus mandatory. To provide this specific and practical training the ERS held a course on paediatric long-term NIV on November 29 and December 1, 2017 in Paris, France.

This course provided a comprehensive overview of the major aspects of paediatric long-term NIV. It focused on practical training of physicians dealing with children with upper airway obstructions that can lead to severe OSAS and neuromuscular and lung diseases that require CPAP or NIV. By attending the course, participants acquired a solid knowledge of the indications, benefits, limits and side-effects of CPAP and NIV for children with OSAS, neuromuscular and lung diseases; the initiation, monitoring and withdrawal of CPAP and NIV in children; and the indications, benefits and limitations of CPAP and NIV in infants under 2 years of age.

Through practical interactive cases, participants learnt how to manage individual patients and understand which equipment (interfaces and devices) should be used for each child, including the different CPAP and NIV modes, when and how to use them, and the advantages and limitations of the different interfaces available. The course further covered different cough assist techniques in children with neuromuscular disease, as well as speech and swallowing difficulties. Participants learnt how to evaluate and manage these problems with high-flow nasal cannula as an alternative to CPAP in selected patients.

The course comprised a mixture of lectures, interactive workshops and hands-on training, as well as a plenary session with a general discussion and multiple case studies (both "basic" and "advanced"). It was targeted towards clinicians (paediatricians, intensive care doctors and pulmonologists) and

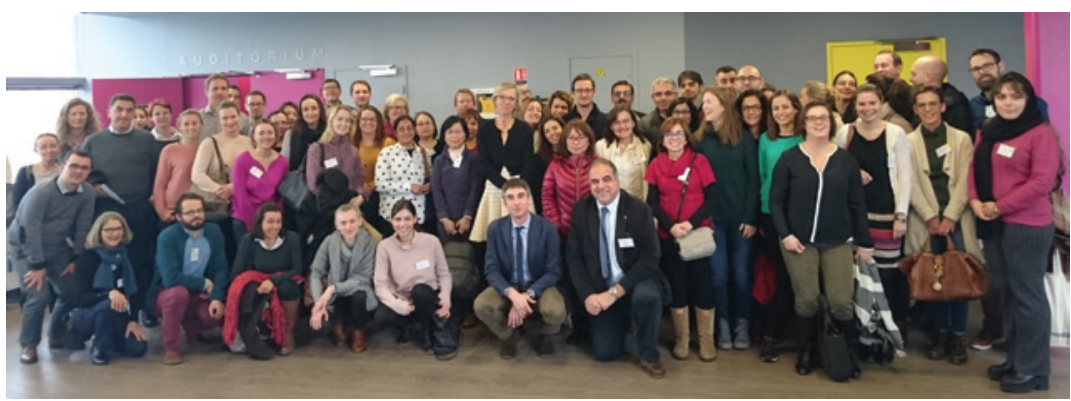

Cite as: Fauroux B, Markovic G. Paediatric long-term noninvasive ventilation: course report. Breathe 2018 ; 14: $91-92$. 
respiratory therapists with no or very limited experience in CPAP/NIV as well as more experienced physicians. 81 participants from 25 different countries took part in the course.

\section{Goran Markovic, Montenegro, a participant}

This course gathered together clinicians who already treat children with NIV and some of us who are at the beginning of our education in this field of medicine. Therefore, it was an excellent opportunity to gain some knowledge and skills and also to make connections with NIV healthcare professionals. All of them expressed unrestricted willingness to help establish and support the use of NIV and cough assist procedures in children.

The course programme was very well planned: the lectures were followed by practical training, where participants could apply and test their theoretical knowledge. The atmosphere at the course was relaxed and friendly, enabling participants to freely discuss their dilemmas with NIV and to compare experiences with faculty members. There were enough opportunities to ask questions after or even during the lectures, with the lecturers willing to help solve many of the

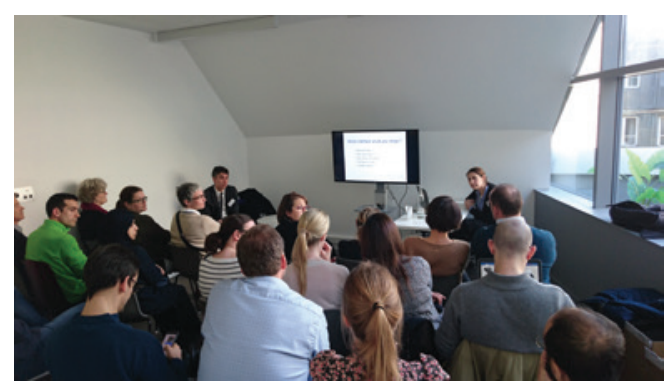

clinical problems that participants are faced with. Nevertheless, the coffee and lunch breaks were also used for discussions, business connections and friendship making.

As most of the participants received their education from the same sources, there weren't many controversies. Lack of the experience and limited financial resources in some countries could be the reason for different NIV treatment practices across Europe.

This course helped me to find out more about the indications for NIV in children, how to apply interfaces, how to set up CPAP and NIV, and how to deal with the most common problems that occur during NIV. In order to apply the knowledge gained from this course, I will need additional education (both theoretical and practical), but thanks to this meeting, I know how and where to ask for that.

\section{Conflict of interest}

B. Fauroux has nothing to disclose. G. Markovic reports a grant from the European Respiratory Society. 